\title{
Nonequivalent roles for motor and visual feedback in the Müller-Lyer and horizontal-vertical illusions
}

\author{
GARY M. BROSVIC, MARGARET FARRELLY, EDWARD REBELE, \\ DONNA RIBARDO, JILL GUTOWSKI, and LOREEN KAFER \\ Rider College, Lawrenceville, New Jersey \\ and \\ ROBERTA E. DIHOFF \\ Rowan College, Glassboro, New Jersey
}

(Michael Epstein, Sponsor)

\begin{abstract}
The relative contributions of motor and visual feedback to illusion decrement for the MüllerLyer (ML) and horizontal-vertical (HV) illusions were estimated after subjects judged the perceived equality of standard and comparison lines with or without visual feedback and after the subject or the experimenter adjusted the comparison line (motor feedback). Visual feedback in the absence of motor feedback reduced magnitude of illusion by $38 \%$ for the ML illusion and by $45 \%$ for the $\mathrm{HV}$ illusion. Motor feedback in the absence of visual feedback reduced magnitude of illusion by $17 \%$ for the ML illusion and by $27 \%$ for the HV illusion. Estimates of "strategic" factors, commonly interpreted as the correction of inaccurate routine problem-solving and judgmental factors, also contain components of motor learning.
\end{abstract}

In prior reports, we described procedure-specific differences in estimates of structural and strategic factors (see Girgus, Coren, Durant, \& Porac, 1975) involved in the Müller-Lyer (e.g., Brosvic et al., 1993) and the horizontal-vertical illusions (e.g., Brosvic \& Cohen, 1988). In these studies, the provision of intertrial feedback resulted in more illusion decrement than did continued visual inspection (CVI), with no synergistic effects observed for the combination of feedback and CVI. Surprisingly, in the absence of feedback and/or CVI, the accuracy of control subjects also improved over repeated testing; this "self-correction" suggests a potential role for motor feedback in the kind of perceptual learning that has been reported in studies employing sensory-motor tasks.

For example, Hagman (1983) examined the effects of combining presentation and test trials on the acquisition and short-term retention of a $250-\mathrm{mm}$ movement by using a linear track apparatus. Potential head movements were minimized by the use of a head- and chinrest, subjects were blindfolded, and experimental instructions were presented through earphones. Performance during the acquisition and retention phases varied as a function of training method, with acquisition influenced most by the alternation of presentation and test trials and retention influenced

Preliminary results of this study were submitted for presentation at the 1993 Annual Meeting of the Eastern Psychological Association. Address correspondence to Gary M. Brosvic, Biopsychology Laboratory, Department of Psychology, Rider College, 2083 Lawrenceville Rd., Lawrenceville, NJ 08648-3099. most by the repeated presentation of test trials. The acquisition of this motor skill in the absence of visual feedback is similar to that reported in a study by Elliott (1988) in which a manual aiming task was used-performance did not differ as a function of viewing or not viewing the stylus when testing consisted of seven trials presented on each of 2 days.

A review of content analyses of subject debriefings from five studies conducted in our laboratory led us to conclude that some portion of illusion decrement contains components of motor learning. Indeed, debriefings conducted immediately after the presentation of repeated test trials (e.g., the drawing of 1-in. horizontal and vertical lines) characterize Adams's (1971) view of motor learning in which successful task performance requires finding the task's best-fitting motor solution. If true, then prior estimates of strategic factors contain components of motor learning, and this outcome has substantial theoretical implications for the structure-strategy dichotomy.

\section{METHOD}

Subjects

Forty-two women and 18 men (ages 19 to 46 years) served as subjects and were drawn from a human subjects pool. Each subject reported normal or corrected $20 / 20$ visual acuity. Thirty subjects were tested on each illusion, with 7 women and 3 men randomly assigned to each group described below.

\footnotetext{
Stimuli

We used the combined Müller-Lyer and horizontal-vertical illusion apparatus produced by Lafayette Instruments (Lafayette, IN). For each
} 
illusion, the metric length of the standard line was $229 \mathrm{~mm}$, whereas that of the comparison line was $381 \mathrm{~mm}$. For the ML illusion, the metric length of the wing-shaft fins was $25.4 \mathrm{~mm}$.

\section{Procedure}

The initial adjustment of a stimulus figure was counted as Minute 0, with additional adjustments made after 60-sec intertrial intervals (ITI). Ten adjustments were made, and prior to each adjustment, the experimenter relocated the comparison line inward/down (100\% too short) or outward/up ( $100 \%$ too long); this order was counterbalanced and half of the subjects began with the line relocated inward (down).

In the motor group, both lines were set to equality and were visually scanned during the 60-sec ITI; on ITI expiration, the subject adjusted the comparison line to apparent equality with the standard. In the nonmotor group, both lines were set to equality and were visually scanned during the 60-sec ITI; on ITI expiration, the experimenter adjusted the comparison line to perceived equality with the standard in accordance with the subject's instructions. The experimenter moved the comparison line left/right (up/down) an equal number of times until the point of subjective equality was identified by the subject. For controls, the stimulus figure was not presented until ITI expiration; on ITI expiration, the subject adjusted the comparison line to perceived equality with the standard, and the stimulus apparatus was removed.

\section{Statistical Analysis}

Mean accuracy scores were calculated by averaging magnitude of illusion across the 10 adjustments. Analyses of variance for repeated measures with Scheffé comparisons were performed for each group to examine potential differences in mean accuracy scores as a function of minute of inspection. Differences in mean accuracy scores between the first and final inspections estimated the relative contributions of inaccurate strategic factors to illusion decrement. The unalterable contributions of structural factors were estimated by residual error. The relative contributions of visual feedback to illusion decrement in the absence of motor feedback were calculated by comparing mean accuracy scores for the nonmotor and motor groups. The relative contributions of motor feedback to illusion decrement in the absence of visual feedback were calculated by comparing mean accuracy scores for the control and motor groups.

\section{RESULTS}

No significant differences in mean accuracy scores as a function of sex of subject were observed, so the data were collapsed across sex for subsequent analysis $[t(28)=0.47, p>.05]$.

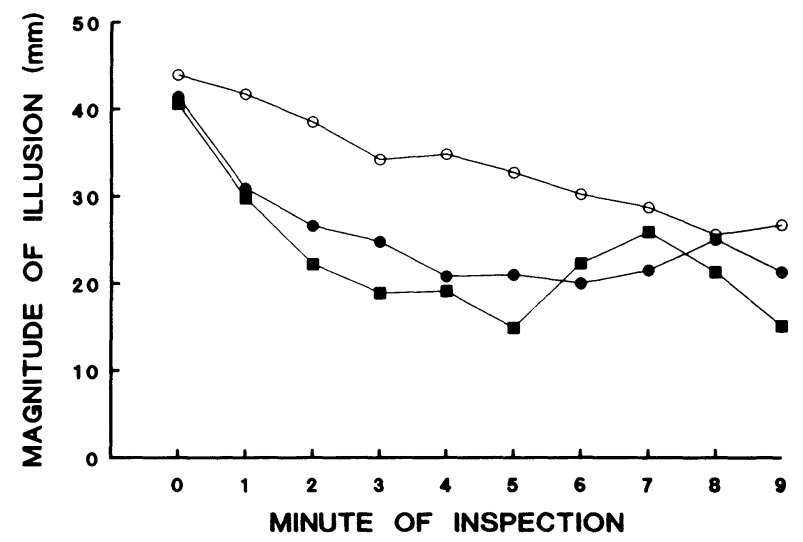

Figure 1. Mean accuracy scores on the Müller-Lyer illusion as a function of minute of inspection for the control (open circles), nonmotor (closed circle), and motor (closed squares) groups.

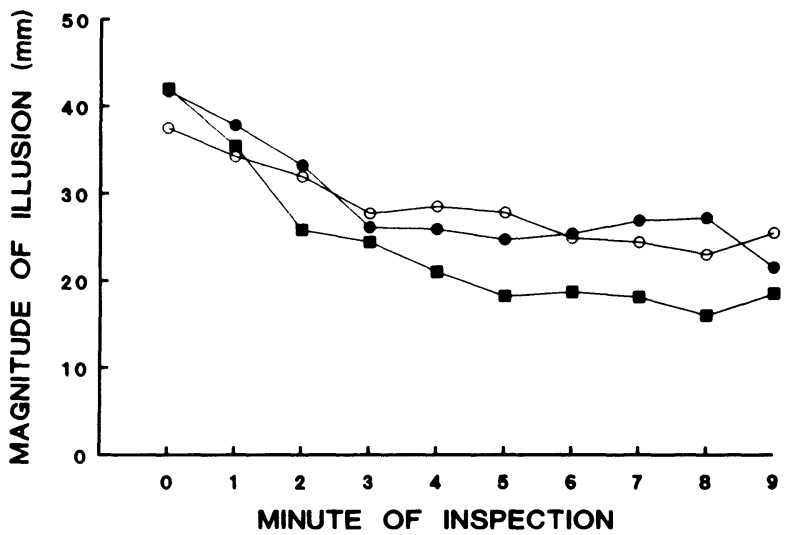

Figure 2. Mean accuracy scores on the horizontal-vertical illusion as a function of minute of inspection for the control (open circles), nonmotor (closed circles), and motor (closed squares) groups.

\section{Müller-Lyer Illusion}

Mean accuracy scores for each group are plotted as a function of minute of inspection in Figure 1. There were no between-group differences in mean accuracy scores at Minute $0[F(2,27)<2.74, p>.05]$; from Minutes 1-6, motor- and nonmotor-group subjects were more accurate than were controls [all $F \mathrm{~s}(2,27)>4.22$, all $p$ s $<.05]$. At the final inspection, motor-group subjects were more accurate than were nonmotor- and controlgroup subjects; nonmotor-group subjects were more accurate than were controls $[F(2,27)=11.33, p<.05]$. Mean illusion decrement was $24 \%, 44 \%$, and $53 \%$ for the control, nonmotor, and motor groups, respectively. The relative contribution of visual feedback to illusion decrement in the absence of motor feedback was $45 \%$, whereas that for motor feedback in the absence of visual feedback was $17 \%$.

\section{Horizontal-Vertical Illusion}

Mean accuracy scores for each group are plotted as a function of minute of inspection in Figure 2. There were no significant between-group differences from Minute 0-Minute $4[F(2,27)<2.84$, all $p$ s $>.05]$. From Minutes 5-9, motor-group subjects were more accurate than were nonmotor group subjects and controls [all $F \mathrm{~s}(2,27)>6.97$, all $p \mathrm{~s}<.05$ ]. Mean accuracy scores did not differ between the motor and nonmotor groups at the final inspection. Mean illusion decrement was $38 \%, 45 \%$, and $61 \%$ for the control, nonmotor, and motor groups, respectively. The relative contribution of visual feedback to illusion decrement in the absence of motor feedback was $38 \%$, whereas that for motor feedback in the absence of visual feedback was $27 \%$.

\section{DISCUSSION}

Magnitude of illusion for the ML illusion was smallest for motorgroup subjects, greatest for controls, and intermediate for nonmotorgroup subjects. Similar results were observed for the HV illusion, 
although at the final inspection, mean accuracy did not differ between the motor and nonmotor groups.

In the absence of visual, but not motor, feedback, controls demonstrated a 23\% (grand median) increase in accuracy. Thus, estimates of strategic factors in this study, and presumably in others, contain components of motor learning developed as a function of repeated practice in a manner similar to that reported for verbal tasks (e.g., Hogan \& Kintsch, 1971). In the absence of motor, but not visual, feedback, nonmotor-group subjects demonstrated a 32\% (grand median) increase in accuracy. For the ML illusion, motor- and nonmotor-group subjects were more accurate than were controls, and there were relatively few differences in accuracy between the nonmotor and motor groups. For the HV illusion, accuracy typically did not differ between the control and nonmotor groups, with more accurate performance demonstrated by motor-group subjects. These results are similar to those of rotary pursuit tracking studies, in which visual feedback yielded more accurate performance than did auditory feedback (C. E. Noble \& C. S. Noble, 1972) and visual feedback increased the mean time spent on target for a manual aiming task following moderate ( 150 trials) levels of practice (Proteau \& Cournoyer, 1990).

The present results taken as a whole suggest nonequivalent roles for motor and visual feedback in the formation of the ML and HV illusions and also suggest that the provision of visual feedback results in the most accurate performance. The mechanisms by which visual feedback, in the absence of knowledge of results, facilitates the correction of inaccurate strategic factors have not been determined and should be addressed in future studies. Experiments are currently being conducted to examine the relative contributions of specialized academic and nonacademic training and experience to susceptibility to the HV illusion.

\section{REFERENCES}

Adams, J. A. (1971). A closed-loop theory of motor learning. Journal of Motor Behavior, 3, 111-150.

Brosvic, G. M., \& CoHEN, B. D. (1988). The horizontal-vertical illusion and knowledge of results. Perceptual \& Motor Skills, 67, 463-469.

Brosvic, G. M., Farrelly, M., Risser, J. M., Shander, J., ClayTON, J., SyPeK, E., Kafer, L., \& Dihoff, R. E. (1993). MüllerLyer Illusion and the structure-strategy dichotomy. Bulletin of the Psychonomic Society, 31, 11-12.

Eluotr, D. (1988). The influence of visual target and limb information on manual aiming. Canadian Journal of Psychology, 41, 57-68.

Girgus, J. S., Coren, S., Durant, M., \& Porac, C. (1975). The assessment of components involved in illusion formation using a longterm decrement procedure. Perception \& Psychophysics, 18, 144-148.

Hagman, J. D. (1983). Presentation and test-trial effect on acquisition and retention of distance and location. Journal of Experimental Psychology: Learning, Memory, \& Cognition, 9, 334-345.

Hogan, R. M., \& KinTsCH, W. (1971). Differential effects of task and test trials on long-term recognition. Journal of Verbal Learning \& Verbal Behavior, 10, 562-567.

Noble, C. E., \& Noble, C. S. (1972). Pursuit tracking skill with separate and combined visual and auditory feedback. Journal of Motor Behavior, 4, 195-205.

Proteau, L., \& Cournoyer, J. (1990). Vision of the stylus in a manual aiming task: the effects of practice. Quarterly Journal of Experimental Psychology, 42B, 811-828.

(Manuscript received August 10, 1992.) 